Vol III. No.2, Maret 2019, hlm. 177 - 181

Available online at www.jurnal.una.ac.id/indeks/jmp

\title{
PENGARUH PENGGUNAAN MEDIA AUDIO VISUAL BERBASIS APLIKASI CAMTASIA TERHADAP HASIL BELAJAR MATEMATIKA SISWA PADA MATERI LOGIKA MATEMATIKA
}

\author{
Eva Margaretha Saragih ${ }^{2}$ \\ ${ }^{1.2}$ Mathematics Education of Asahan University, Indonesia. \\ agethaevasaragih@gmail.com
}

\begin{abstract}
This study aims to determine whether there is an effect of the use of Camtasia-based audio visual media on students' mathematics learning outcomes in class XI Mathematical Logic Material of Muhammadiyah 5 Vocational School in Asahan Regency 2016/2017 Academic Year. This type of research is quasiexperimental, which is the sample of the study there are 2 classes (class XI AP-1 and XI AP-2) taken in cluster random.

Then given a different treatment, the experimental class with the conventional Visual Assisted Media Learning learning model and the control class with conventional methods. After the learning was completed, posttest was obtained with the results of the experimental class averages 78.7 and the control class 74.7. The results of $t$-test obtained thitung $=2.10>t$ table $=1.67$ then $\mathrm{Ha}$ is accepted, thus it can be concluded that there is influence of the use of Camtasia-based Audio Visual Media on Student Mathematics Learning Outcomes in Class XI Mathematical Logic Material of Muhammadiyah 5 Kisaran District Asahan 2016/2017 Academic Year.
\end{abstract}

Keywords: Use of Camtasia Application-Based Audio Visual Media, learning outcomes, Mathematical Logic.

\begin{abstract}
Abstrak
Penelitian ini bertujuan untuk mengetahui apakah terdapat Pengaruh Penggunaan Media Audio Visual Berbasis Aplikasi Camtasia Terhadap Hasil Belajar Matematika Siswa Pada Materi Logika Matematika Kelas XI SMK Swasta Muhammadiyah 5 Kisaran Kabupaten Asahan Tahun Ajaran 2016/2017. Jenis penelitian ini adalah quasi eksperimen, yang menjadi sampel penelitian ada 2 kelas (kelas XI AP-1 dan XI AP-2) yang diambil secara cluster random.

Kemudian diberikan perlakuan berbeda, kelas eksperimen dengan model pembelajaran Konvensional Berbantukan Media Audio Visual dan kelas kontrol dengan metode konvensional. Setelah pembelajaran selesai diberikan, diperoleh postes dengan hasil rata- rata kelas eksperimen 78,7 dan kelas kontrol 74,7. Hasil uji $\mathrm{t}$ diperoleh $\mathrm{t}_{\text {hitung }}=2,10>\mathrm{t}_{\text {tabel }}=1,67 \mathrm{maka}_{\mathrm{a}}$ diterima, dengan demikian dapat disimpulkan bahwa ada pengaruh Penggunaan Media Audio Visual Berbasis Aplikasi Camtasia Terhadap Hasil Belajar Matematika Siswa Pada Materi Logika Matematika Kelas XI SMK Swasta Muhammadiyah 5 Kisaran Kabupaten Asahan Tahun Ajaran 2016/2017.
\end{abstract}

Kata Kunci : Penggunaan Media Audio Visual Berbasis Aplikasi Camtasia, hasil belajar, Logika Matematika. 
Vol III. No.2, Maret 2019, hlm. 177 - 181

Available online at www.jurnal.una.ac.id/indeks/jmp

\section{PENDAHULUAN}

Pendidikan yang mampu mendukung pembangunan dimasa mendatang adalah pendidikan yang mampu mengembangkan potensi peserta didik, sehingga yang bersangkutan mampu menghadapi dan memecahkan problema kehidupan yang dihadapinya. Pendidikan harus menyentuh potensi nurani maupun potensi kompetensi peserta didik.

Menurut Trianto (2011:4) berpendapat bahwa upaya yang tepat untuk menyiapkan sumber daya manusia (SDM) yang berkualitas dan satu - satunya wadah yang dapat dipandang dan seyogianya berfungsi sebagai alat untuk membangun SDM yang bermutu tinggi adalah pendidikan. Maka pendidikan adalah satu - satunya aset untuk membangun sumber daya manusia (SDM) yang berkualitas. Oleh karena itu, diperlukan inovasi bagaimana pendidikan bisa menjadi sarana untuk membuka pola pikir siswa agar lebih memahami suatu konsep dalam pembelajaran.

Oleh karena itu, perlu adanya perubahan cara mengajar dari model pembelajaran tradisional menuju pembelajaran inovatif serta melibatkan siswa secara aktif, bukan menjadikan siswa sebagai objek. Metode yang digunakan pun bukan lagi yang bersifat monoton. Melainkan bersifat fleksibel dan dinamis. Matematika merupakan salah satu bidang ilmu pokok dalam dunia pendidikan yang sangat penting, baik bagi peserta didik maupun pengembangan bidang ilmu lainnya serta dalam kehidupan masyarakat. Bahwa masih banyak siswa yang mengalami kesulitan dalam mempelajari ilmu matematika. Dengan kegiatan belajar mengajar selalu didominasi oleh siswa-siswa tertentu saja, sedangkan siswa yang lain tidak aktif. Bahkan tak jarang pada saat proses belajar mengajar siswa sering mengerjakan tugas diluar mata pelajaran matematika. Hasil belajar matematika siswa yang ditunjukkan dari rata-rata hasil nilai ujian nasional (UN) masih sangat rendah jika dibandingkan dengan mata pelajaran lainnya seperti bahasa indonesia dan bahasa inggris. Dalam hal tersebut dapat dilihat dengan tabel 1.1. sebagai berikut:

Tabel 1.1. Rata-rata Hasil Ujian Nasional (UN).

\begin{tabular}{|l|c|c|c|}
\hline \multicolumn{4}{|c|}{ Tahun } \\
\hline Mata Pelajaran & 2013 & 2014 & 2015 \\
\hline Bahasa Indonesia & 78,45 & 76,67 & 79,95 \\
\hline Bahasa Inggris & 72,88 & 74,66 & 73,26 \\
\hline Matematika & 66,98 & 67,66 & 68,44 \\
\hline
\end{tabular}

Dari tabel diatas dapat dilihat siswa masih kesulitan dalam proses pembelajaran. Hal ini terjadi karena siswa merasa jenuh dengan apa yang disampaikan guru pada saat proses belajar mengajar yang setiap pertemuannya 
Vol III. No.2, Maret 2019, hlm. 177 - 181

Available online at www.jurnal.una.ac.id/indeks/jmp

hampir melakukan hal yang sama yaitu menyampaikan materi yang akan dipelajari dan langsung memberi tugas terhadap siswa. Diskusi kelompok jarang dilakukan sehingga interaksi dan komunikasi antara siswa dengan siswa lainnya maupun dengan guru masih belum terjalin sepenuhnya selama proses pembelajaran. Hal ini seharusnya menjadi patokan bahwa pembelajaran matematika harus lebih ditingkatkan untuk mencapai hasil yang diinginkan. Selain untuk memenuhi kriteria penilaian kelulusan untuk tingkat sekolah/pendidikan, namun peran matematika juga mampu meningkatkan cara berfikir manusia secara logis, cermat, serta bersifat objektif dan mampu menyelesaikan permasalahan yang ada.

Berdasarkan uraian diatas, maka penulis tertarik untuk mengadakan penelitian. Adapun judul penelitian adalah: Pengaruh Penggunaan Media Audio Visual Berbasis Aplikasi Camtasia Terhadap Hasil Belajar Matematika Siswa Pada Materi Logika Matematika Kelas XI SMK Swasta Muhammadiyah 5 Kisaran Tahun Ajaran 2016/ 2017.

Camtasia adalah software atau perangkat lunak yang dikembangkan oleh Tech Smith coorporation. Camtasia digunakan untuk merekam semua aktifitas yang ada pada desktop komputer. Software ini bisa kita manfaatkan untuk membuat media pembelajaran berbasis multimedia dan elearning. Dalam software ini terdapat navigasi utama yang perlu kita pahami agar kita dapat menggunakan dan memahami software ini, navigasi utama tersebut adalah :

a. Record berfungsi untuk merekam aktivitas atau kegiatan pada dekstop komputer.

b. Edit berfungsi untuk mengedit hasil rekaman yang sebelumnya telah direkam pada dekstop komputer.

c. Produce berfungsi untuk memproduksi hasil rekaman yang telah direcord serta diedit sebelumnya.

d. Share berfungsi sebagai finishing atau ketiga poin diatas kita bisa share hasil record yang telah dibuat kedalam bentuk CD, DVD, atau menyimpannya kedalam blog atau web yang kita punya.

\section{METODE}

Penelitian ini dilaksanakan dikelas XI siswa SMK Swasta Muhammadiyah 5 Kisaran Tahun Ajaran 2016 / 2017 yang waktu penelitiannya dilaksanakan pada semester genap tahun ajaran 2016 / 2017.

Dalam hal ini yang menjadi populasi penelitian adalah seluruh siswa kelas XI SMK Swasta Muhammadiyah 5 Kisaran . Populasi sebanyak 90 siswa yang terbagi dalam 3 
Vol III. No.2, Maret 2019, hlm. 177 - 181

Available online at www.jurnal.una.ac.id/indeks/jmp

kelas. dan masing-masing kelas berjumlah 30 siswa.

Desain penelitian ini menggunakan metode quasi eksperimen. Sampel penelitian yang digunakan terdiri dari dua kelas yaitu kelas eksperimen dan kelas kontrol, kelas eksperimen diajar dengan menggunakan media audio visual berbasis aplikasi camtasia dan kelas kontrol diajarkan dengan metode konvensional.

\section{Tabel 3.1 Two Group Pretest - postest Design}

\begin{tabular}{l|c|c|c}
\hline Kelas & Pretest & perlakuan & Postest \\
Eksperimen & $\mathrm{O}_{1}$ & $\mathrm{X}_{1}$ & $\mathrm{O}_{2}$ \\
Kontrol & $\mathrm{O}_{1}$ & $\mathrm{X}_{1}$ & $\mathrm{O}_{2}$ \\
\hline
\end{tabular}

\section{HASIL DAN PEMBAHASAN}

Hasil penelitian pada pengaruh penggunaan media audio visual berbasis aplikasi camtasia terhadap hasil belajar matematika siswa pada materi Logika matematika kelas XI SMK Swasta Muhammadiyah 5 Kisaran Tahun ajaran 2016/2017. Disekolah ini terdapat 3 rombel untuk kelas XI, 2 rombel ini merupakan sampel penelitian sebanyak 60 siswa, dibagi menjadi kelas XI AP-1 sebanyak 30 siswa dan kelas XI AP-2 sebanyak 30 siswa.

Metode test digunakan untuk mengetahui kemampuan siswa dalam memahami pokok bahasan logika matematika. Test ini sebelumnya sudah diujikan pada validator. Tes tersebut diberikan kepada kelas sampel yaitu siswa kelas XI AP-1 sebagai kelas

eksperimen yang diajar dengan menggunakan media audio visual berbasis aplikasi camtasia dan kelas XI AP-2 sebagai kelas kontrol yang diajar dengan menggunakan model pembelajaran konvensional. Metode observasi digunakan untuk melihat dan menganalisis hasil belajar dalam pembelajaran. Test berupa soal pilihan berganda yang sebelumnya telah diuji validitas, reliabilitas, daya pembeda, dan tingkat kesukaran dengan menggunakan secara rumus analisis manual di Ms. Excel.

Berdasarakan hasil penelitian dan pembahasan yang dikemukakan pada bab IV, ditemukan bahwa nilai rata-rata hasil belajar siswa pada kelas XI AP-1 adalah 78,7 dan kelas XI AP-2 adalah 74,7. Berdasarkan hasil perhitungan juga menunjukkan bahwa $t_{\text {hitung }}$ $(2,10)$ lebih besar dari pada nilai tabel $(1,67)$ pada taraf signifikan $\alpha=0,05$. Dengan demikian dapat disimpulkan bahwa terdapat Pengaruh Penggunaan Media Audio Visual Berbasis Aplikasi Camtasia Terhadap Hasil Belajar Matematika Siswa Pada Materi Logika Matematika Kelas XI SMK Swasta Muhammadiyah 5 Kisaran Tahun Ajaran 2016/2017. 
Vol III. No.2, Maret 2019, hlm. 177 - 181

Available online at www.jurnal.una.ac.id/indeks/jmp

\section{SIMPULAN}

Dari hasil analisis data yang dilakukan dalam penelitian ini dapat diambil kesimpulan sebagai berikut :

a. Dengan Penggunaan Media Audio Visual Berbasis Aplikasi Camtasia, siswa lebih memahami dalam pembelajaran Logika Matematika, dikarenakan siswa lebih aktif

\section{DAFTAR RUJUKAN}

Arikunto, S. 2012. Dasar- Dasar Evaluasi Pendidikan. Jakarta: PT. Bumi Aksara.

Cunayah, C. 2015. Bank Soal Bimbingan Pemantapan Matematika SMA/MA. Bandung: Penerbit Yrama Widya.

Kholiqul, A. 2013.Pembuatan Video Tutorial Menggunakan Camtasia Studio 6. Program Komputer IKIP PGRI Bojonegoro.

Kurnianingsih, 2007. Matematika SMA dan MA. Jakarta: PT. Gelora Aksara Pratama Erlangga.

Slameto. 2010. Belajar dan Faktor-Faktor Yang Mempengaruhi. Jakarta : Rineka Cipta. dalam proses pembelajaran dan dapat menumbuhkan pemikiran yang kritis.

b. Rata-rata hasil belajar matematika siswa pada pembelajaran dengan menggunakan Media Audio Visual Berbasis Aplikasi Camtasia pada materi Logika Matematika menunjukkan rata-rata yang lebih tinggi di kelas eksperimen sedangkan rata-rata di kelas kontrol lebih rendah.

Sabri. 2014. Strategi Belajar Mengajar Micro Teaching. Ciputat : PT. Ciputat Press.

Sudjana, N. 2009. Penelitian Hasil Proses Belajar Mengajar. Bandung: PT. Remaja Rosdakarya.

Sudjana. 2009. Metoda Statistika. Bandung : PT. Tarsito Bandung.

Sugiyono. 2014. Metodologi Penelitian Pendidikan. Bandung : Alfabeta.

Sapta, A. 2011. Peningkatan Penguasaan Nilai Sudut Trigonometri Dengan Menggunakan Domino Trigonometri. Jurnal Mathematics Paedagogic, I (2): 113-124.

Trianto. 2011. Mendesain Model Pembelajaran Inovatif-Progresif. Jakarta : Kencana Prenada Media Group. 